\title{
Heterogeneity of Segregation Ratios from Selfed Progenies Demonstrate Polygenic Inheritance for Day Neutrality in Strawberry (Fragaria Xananassa Duch.)
}

\author{
Douglas V. Shaw \\ Department of Pomology, University of California, Davis, CA 95616
}

\begin{abstract}
AdDitional INDEX WORDS. photoperiodism, everbearing, June-bearing, short-day, genetics
Aвstract. Selfed progenies were generated using 10 day-neutral genotypes from the University of California (UC) strawberry breeding program as parents and their offspring were classified for late-summer flowering response. The grandparents of each selfed progeny included one of four day-neutral genotypes and one of eight short-day genotypes. Under the null hypothesis of genetic control by a single locus with the allele for day-neutrality dominant to the allele for short-day flowering response, all of these day-neutral parent genotypes must be heterozygous and their selfed offspring were expected to fit a 3:1 ratio of day-neutral : short-day phenotypes. The percentage of day-neutral offspring observed over all progenies was $70.9 \%$, and was significantly smaller than the expected value of $75 \%\left(\chi_{1}^{2}=5.08, P\right.$ $<0.02$ ). The percentage of day-neutral offspring for individual progenies ranged from $41.4 \%$ to $84.8 \%$, and highly significant heterogeneity was detected among progenies $\left(\chi_{9}^{2}=40.3, P<0.01\right)$. Selfed progeny means for the cumulative late-summer flowering score calculated using the day-neutral fraction of offspring varied from 1.31 to 2.35 and progeny means for the number of inflorescences per plant ranged from 3.5 to 9.9; these differences among progenies were highly significant $(P<\mathbf{0 . 0 1})$. These observations can be used to conclusively reject the hypothesis that day-neutrality in this domestic strawberry population is controlled by a single locus.
\end{abstract}

The genetics of photoperiod insensitivity, or day-neutrality, for flowering in domestic strawberry (Fragaria $\times$ ananassa Duch.) has been studied extensively due to its importance in commercial production systems (see Hancock et al., 2002, for a summary). Despite substantial research effort on this topic dating to the early 1900s, experiments have provided conflicting results and the mode of inheritance for photoperiodism in strawberry remains largely unresolved.

Although environmental factors can have large effects on the induction, development, and differentiation of inflorescences in strawberry, the presence or absence of late-summer flowering often permits discrete classification of genotypes. The best fit to a categorical model postulating simple inheritance of photoperiodism was provided by the extensive results obtained by Ahmadi et al. (1990), where segregation ratios for a number of cross types fit an hypothesis of genetic control by a single locus with the allele for day-neutrality dominant to the allele for short-day flowering response. The results of Scott (1936) also suggested simple inheritance of day-neutrality, although the allele for photoperiod insensitivity was postulated to be recessive rather than dominant. Classification of genotypes as short-day or day-neutral in these and other studies was based on several different evaluation methods, results were obtained in differing locations and test environments, and it is unclear which criteria were applied in each experiment. Taken together, these studies provide inconclusive and somewhat contradictory evidence for classical segregation of photoperiodism.

Support for a polygenic mode of inheritance for day-neutrality in domestic strawberry and its octoploid wild progenitors derives from the failure of the offspring from specifically designed crosses to fit segregation ratios for day-neutral and short-day phenotypes expected from single-locus models (Ourecky and Slate, 1967; Powers, 1954). Further evidence for complex inheritance of day neutrality derives from observations of a continuous distribu-

Received for publication 25 Nov. 2002. Accepted for publication 10 Mar. 2003. tion of segregation ratios from populations of controlled crosses (Clark, 1938; Hancock et al., 2002; Nicoll and Galletta, 1987). These studies have been used to support a range of genetic models, including those that propose two loci with dominance and epistasis, and more classical highly polygenic models. Further indirect evidence for complex inheritance of day-neutrality derives from investigations of the physiology of strawberry flowering response. These results typically show a range of responses to daylength that both differs among genotypes and interacts with other environmental factors, especially temperature (Durner et al., 1984; Heide, 1977).

Regardless of the genetic hypothesis proposed, all of the studies cited above acknowledge the confounding effects of environmental and cultural factors on photoperiodism for flowering in strawberry (Durner et al., 1984; Larson, 1994). The effects of non-genetic factors other than daylength are expressed in the inheritance studies cited above either as the failure to detect distinct classes of flowering types (Nicoll and Galletta, 1987) or as the concern for sources of mis-classification of genotypes despite a perception of distinct flowering-type categories (Ahmadi et al., 1990). Hancock et al. (2002) concluded that, taken together, the available experimental results for studies of day-neutrality in strawberry fit several alternative genetic hypotheses, including a polygenic threshold model.

A feature common in the segregation studies cited above is that offspring information frequently was pooled over several crosses for a single putative cross category or type (e.g., putative day-neutral heterozygote $\times$ short-day crosses). With incomplete dominance and partial penetrance due to environmental effects, similar segregation ratios can fit several genetic hypotheses equally well (Elandt-Johnson, 1971), including both single locus and polygenic models. The power to detect deviations from the hypothesis of single-locus inheritance will be limited in such cases, but may be especially compromised when offspring information is pooled over both crosses and evaluation environments. The study reported below was conducted to determine whether a single-locus hypothesis for inheritance of day neutrality could be 
Table 1. Pedigree information for 10 day-neutral genotypes used as parents of selfed progenies for segregation analysis.

\begin{tabular}{|c|c|}
\hline Genotype & Pedigree \\
\hline Cal 95.79-5 & Cal 91.248-3z x Cal 91.269-1 \\
\hline Cal 95.142-1 & Cal $91.248-5$ x Cal 90.241-5z \\
\hline Cal 95.145-2 & Cal 91.326-1 x Cal 90.241-5z \\
\hline Cal 95.154-4 & Cal $91.248-5$ x Cal 91.238-2z \\
\hline Cal 96.146-1 & Cal $91.248-5 \times$ Cal 91.238-2z \\
\hline Cal 96.207-3 & Cal 91.248-6z x Cal 92.289-4 \\
\hline Cal 96.240-2 & Cal $90.241-5^{z}$ x Cal 92.289-6 \\
\hline Cal 97.78-11 & Cal 91.248-6z x Cal 92.63-2 \\
\hline Cal 97.79-14 & Cal 91.248-6z x Cal 92.245-2 \\
\hline Cal 97.117-3 & Cal 91.248-6 x Cal 94.16-1 \\
\hline
\end{tabular}

zThe day-neutral parent in each pedigree.

excluded based on the heterogeneity of segregation ratios within a single cross category.

\section{Materials and Methods}

Ten day-neutral genotypes were chosen from the Univ. of California strawberry improvement program based on their flowering phenotypes and their genetic background. Each of the 10 genotypes was an advanced selection in test for possible commercial release and had flowered in the long days of summer during runner plant propagation at two nursery locations: the Univ. of California, Davis, Wolfskill Experimental Orchard near Winters, Califo. (lat. 38 30' N, long. 121 59' W, elevation 41 m), and Lassen Canyon Nursery near Macdoel, Calif. (lat. 41 45' N, long. $1222^{\prime}$ W, elevation $1290 \mathrm{~m}$ ). As a further restriction, each of these parent genotypes traced to a cross between one day-neutral and one short-day genotype (Table 1). Four different day-neutral genotypes that also met the above nursery flowering criteria and eight short-day genotypes that never flowered at either nursery location were represented in the immediate genetic background of the parental selections.

Progenies were generated for each of the day-neutral genotypes in January 2001 using a single generation of self-fertilization. Seedlings from each of the progenies were established in field trials on 27 Sept. 2001, at the Wolfskill Experimental Orchard and cultured as described previously (Shaw, 1995). The trial was established after pre-plant soil fumigation using 2 methyl bromide: 1 chloropicrin (wt/wt), at $392 \mathrm{~kg} \cdot \mathrm{ha}^{-1}$; seedlings were grown on two-row diagonal raised beds with $150-\mathrm{cm}$ centers and $34-\mathrm{cm}$ plant spacing along rows (34,270 plants per hectare). A Randomized Complete Block design was used, with a single plot of 30 to 40 seedlings from each cross in each of two blocks.

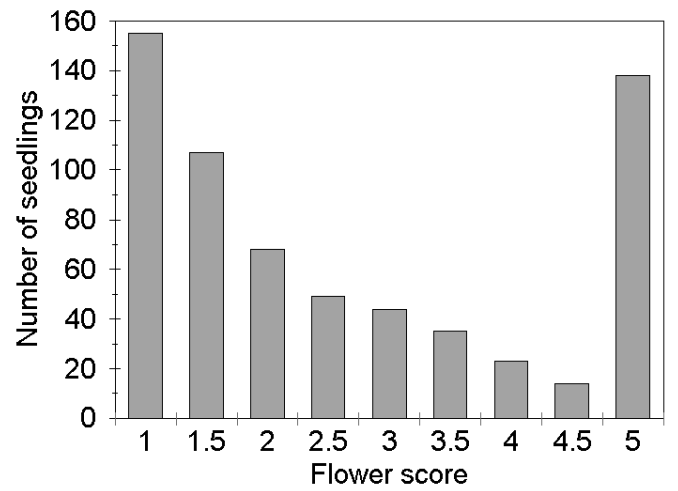

Fig. 1. Frequency distribution of late-summer flowering scores for 10 selfed strawberry progenies.
Individual seedlings were scored for the presence of flowers or fruit on 8 May 2002; >95\% of the seedlings were flowering or fruiting on that date, thus this variable was not considered further. Late-summer flowering was evaluated by assigning a subjective flowering score and by counting the number of recently emerged inflorescences per seedling on 6 and 22 Aug. 2002. The subjective flowering score was assigned on a 1 to 5 scale about as follows: $5=$ no flowers or fruit, $4=$ fruit but no recently emerged inflorescences, $3=$ at least one recently emerged inflorescence, $2=2$ to 3 recently emerged inflorescences, $1=$ more than 3 recently emerged inflorescences. Individuals assigned a value of $\leq 3$ were considered possible day-neutral genotypes. Combined variables were compiled and used for further analyses by averaging the subjective flowering score and summing the inflorescence numbers across the two observation dates. For segregation analysis, individual seedlings were classified as day-neutral if they had a score of $\leq 3$ on either date, i.e., at least one recently emerged inflorescence on either late summer evaluation date. To reduce mis-classification of late-flowering short-day genotypes, the ten individuals that produced a single inflorescence on the $6 \mathrm{Aug}$. date only were re-evaluated on 4 Sept., and eight of these seedlings were reclassified as SD types due to the absence of continued flowering.

Under the null hypothesis of genetic control by a single locus with the allele for day-neutrality dominant to the allele for short-day flowering response, all of the selections must be heterozygous, and their selfed offspring were expected to fit a $3: 1$ ratio of day-neutral : short-day phenotypes. Chi-square statistics were calculated to test the fit of the overall segregation ratio to this 3:1 expectation, and to test the homogeneity of segregation ratios across the 10 progenies. To further quantify the flowering response, comparisons were made among progenies for flowering score and inflorescence number using only those offspring classified as day-neutral. Progenies were compared for these variables using ANOVA and Bonferonni's pairwise post-hoc comparisons (SAS Institute, 1990).

\section{Results and Discussion}

Frequency distributions for the entire population of seedlings were bimodal for both average flowering score (Fig. 1) and the number of inflorescences (Fig. 2). A sharp peak was present for both variables, indicating the absence of late-summer flowering, and a much broader peak was present that depicts substantial variation for each variable within the day-neutral subset. There was no evidence of further modality within the subset of day-neutral genotypes for either trait, although the

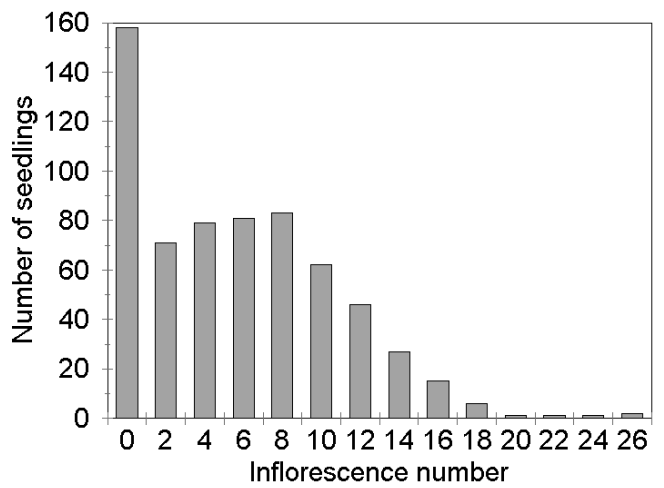

Fig. 2. Frequency distribution of late-summer inflorescence numbers for 10 selfed strawberry progenies. 
Table 2. Segregation analysis for the frequency of day-neutral offspring in ten selfed strawberry progenies, including $\chi^{2}$ tests for goodness of fit to an expected of segregation ratio of $3: 1$.

\begin{tabular}{lccc}
\hline $\begin{array}{l}\text { Parent } \\
\text { genotype }\end{array}$ & $\mathrm{N}$ & $\begin{array}{c}\text { Day-neutral } \\
(\%)\end{array}$ & $\begin{array}{c}\chi^{2} \text { for fit to } \\
\text { a 3:1 ratio }\end{array}$ \\
\hline Cal 95.79-5 & 60 & 78.3 & 0.39 \\
Cal 95.142-1 & 79 & 84.8 & $5.90^{*}$ \\
Cal 95.145-2 & 74 & 82.4 & 2.82 \\
Cal 95.154-4 & 68 & 76.5 & 0.08 \\
Cal 96.146-1 & 61 & 68.9 & 1.07 \\
Cal 96.207-3 & 51 & 74.5 & 0.01 \\
Cal 96.240-2 & 66 & 68.2 & 1.41 \\
Cal 97.78-11 & 55 & 67.3 & 1.49 \\
Cal 97.79-14 & 58 & 41.4 & $27.02^{* *}$ \\
Cal 97.117-3 & 61 & 59.0 & $6.44^{*}$ \\
All progenies & 633 & 70.9 & $5.08^{*}$ \\
\hline ***Significant deviation from a 3.1 ratio at $P<0.05$ or 0.01, respectively.
\end{tabular}

Table 3. Progeny sample sizes, means $( \pm \mathrm{SD})$ for late-summer flowering score and the late-summer inflorescence numbers, using only seedlings classified as day-neutral from 10 selfed progenies.

\begin{tabular}{lccc}
\hline Parent genotype & $\mathrm{N}$ & Flowering score & Inflorescence no. \\
\hline Cal 95.79-5 & 47 & $1.31 \pm 0.52 \mathrm{a}^{\mathrm{z}}$ & $9.7 \pm 3.6 \mathrm{de}$ \\
Cal 95.142-1 & 67 & $1.44 \pm 0.76 \mathrm{ab}$ & $9.8 \pm 4.6 \mathrm{e}$ \\
Cal 95.145-2 & 61 & $1.49 \pm 0.69 \mathrm{abc}$ & $9.9 \pm 5.3 \mathrm{e}$ \\
Cal 95.154-4 & 52 & $1.79 \pm 0.68 \mathrm{bcd}$ & $6.5 \pm 2.7 \mathrm{bc}$ \\
Cal 96.146-1 & 42 & $2.05 \pm 0.74 \mathrm{de}$ & $5.9 \pm 2.8 \mathrm{abc}$ \\
Cal 96.207-3 & 38 & $1.68 \pm 0.65 \mathrm{abcd}$ & $7.3 \pm 3.3 \mathrm{~cd}$ \\
Cal 96.240-2 & 45 & $1.89 \pm 0.73 \mathrm{cde}$ & $6.4 \pm 2.9 \mathrm{abc}$ \\
Cal 97.78-11 & 37 & $1.85 \pm 0.78 \mathrm{bcde}$ & $6.4 \pm 3.3 \mathrm{abc}$ \\
Cal 97.79-14 & 24 & $2.94 \pm 0.71 \mathrm{f}$ & $3.5 \pm 1.9 \mathrm{a}$ \\
Cal 97.117-3 & 36 & $2.35 \pm 0.77 \mathrm{ef}$ & $4.5 \pm 2.3 \mathrm{ab}$ \\
All progenies & 449 & $1.78 \pm 0.80$ & $7.5 \pm 4.1$ \\
\hline
\end{tabular}

zValues for each trait not followed by a common letter differ significantly $(P<$ 0.05) based on a Bonferonni's post-hoc comparison.

flowering scores in this subset were heavily skewed towards strong flowering.

Three of the 10 individual-progeny segregation ratios showed significant $(P<0.05)$ or highly significant $(P<0.01)$ deviation from that expected for the single locus hypothesis (Table 2). Of these three, an excess of day-neutral genotypes was found in the offspring of Cal 95.145-2 and deficiencies were detected for the offspring of Cal 97.79-14 and Cal 97.117-3. The observation of significant lack of fit due to both excesses and deficiencies of day-neutral seedlings is not consistent with an explanation based on scoring or environmental biases.

The percentage of day-neutral offspring averaged over all progenies was $70.9 \%$ (Table 2) and this value also differed significantly from the expected value due to a single locus hypothesis of $75 \%\left(\chi_{1}^{2}=5.08, P<0.02\right)$. Most importantly, the percentage of day-neutral offspring for individual progenies ranged from $41.4 \%$ to $84.8 \%$ (Table 2 ), and highly significant heterogeneity was detected among these sets of offspring $\left(\chi^{2}=40.3, P<0.01\right)$. These observations can be used to conclusively reject the hypothesis that day-neutrality in this domestic strawberry population is controlled by a single locus.

The day-neutral offspring from each progeny were compared for quantitative measures of flower production to further evaluate the inheritance of flowering intensity within this subset. Selfed progeny means for the average flowering score ranged from 1.31 to 2.35 and progeny means for the number of inflorescences per plant ranged from 3.5 to 9.9 (Table 3), demonstrating considerable variation in quantitative flowering responses for day-neutral seedlings from heterogeneous crosses. Furthermore, the progeny means for flowering variables were not independent of the progeny segregation ratios. Specifically, the correlation between progeny means for the number of inflorescences per plant in the day-neutral fraction and the percentage of seedlings classified as day-neutral was $r=0.90(P<0.01)$, which suggests that the genes conditioning the strength of flowering are largely the same as those that control the presence or absence of late season flowering. This last result is consistent with a polygenic threshold model, but is not consistent with a single-locus model that postulates dominance for day-neutrality.

Results from ANOVAs for flowering score and the number of inflorescences per plant demonstrated that the among-progeny differences detailed above were highly significant (Table 4). Variances due to progeny mean differences accounted for $25 \%$ to $26 \%$ of the experimental phenotypic variation. Assignment of genetic variance components is impossible for this sample due to truncation of the data set and the use of self-fertilized progenies, but with the simplest genetic models (Falconer and Mackay, 1996) about half of the phenotypic variance detected would be genetic in origin.

Ultimately, both the capacity to sustain late-summer flowering and the magnitude of late summer fruit production will be important considerations in developing commercially useful strawberry cultivars. My results do not preclude the possibility that loci with large effects contribute to genetic variation for these characteristics, but classical segregation analysis is unlikely to be a powerful tool in resolving the effects of such loci. Furthermore, the detection of substantial differences among progenies for quantitative measures of flower production in their day-neutral offspring suggests that the flowering response is highly complex and future focus on segregation ratios rather than the flowering variables themselves may be misplaced. From a pragmatic perspective, the goal might be to first set appropriate targets for genetic improvement in terms of late-summer inflorescence numbers or fruit production parameters, then use more trait-based methods, such as complex segregation analysis (Tourjee et al., 1995) to quantify the relevant variation.

Table 4. Results for analysis of variance for late-summer flowering score and the late-summer inflorescence numbers, using only seedlings classified as day-neutral from 10 selfed progenies.

\begin{tabular}{lrcccc}
\hline & & \multicolumn{2}{c}{ Flowering score } & \multicolumn{2}{c}{ Inflorescence number } \\
\cline { 3 - 6 } Source & df & Mean square & $\sigma^{2}(\%)^{z}$ & Mean square & $\sigma^{2}(\%)^{z}$ \\
\hline Replication (R) & 1 & $5.54^{* *}$ & --- & $76.6^{*}$ & $4.4(25)$ \\
Progeny (P) & 9 & $7.68^{* *}$ & $0.17(26)$ & $203.6^{* *}$ & $0.4(2)$ \\
R $\times$ P & 9 & 0.67 & $0.01(2)$ & 20.0 & 12.8 \\
Within progeny & 429 & 0.48 & $0.48(72)$ & $12.8(73)$ \\
\hline
\end{tabular}

${ }^{2}$ Values in parentheses are percentage of the experimental phenotypic variance after correction for common block effects.

****Significant deviation from a $3: 1$ ratio at $P<0.05$ or 0.01 , respectively. 


\section{Literature Cited}

Ahmadi, H., R.S. Bringhurst, and V. Voth. 1990. Modes of inheritance of photoperiodism in Fragaria. J. Amer. Soc. Hort. Sci. 115:146-152.

Clark, J.H. 1938. Inheritance of the so called everbearing tendency in strawberry. Proc. Amer. Soc. Hort. Sci. 35:67-70.

Durner, E.F., J.A. Barden, D.G. Himelrick, and E.B. Poling. 1984. Photoperiod and temperature effects on flower and runner development in day-neutral, June-bearing, and everbearing strawberries. J. Amer. Soc. Hort. Sci. 109:396-400.

Elandt-Johnson, R.C. 1971. Probability models and statistical methods in genetics. Wiley, New York.

Falconer, D.S. and T. Mackay. 1996. Introduction to quantitative genetics. Longman Press. New York.

Nicolle, M. and G.J. Galletta. 1987. Variation in growth and flowering habit of Junebearing and everbearing strawberries. J. Amer. Soc. Hort. Sci. 112:872-880.

Hancock, J.F., J.J. Luby, A. Dale, P.W. Callow, S. Serce, and A. El-Sheik. 2002. Utilizing Fragaria virginiana in strawberry cultivar development: Inheritance of photoperiod sensitivity, fruit size, gender, female fertility, and disease resistance. Euphytica 126:177-184.

Heide, O.M. 1977. Photoperiod and temperature interactions in growth and flowering of strawberry. Physiol. Plant. 40:21-26.

Larson, K.D. 1994. Strawberry, p. 271-297. In: B. Schaffer and P.C. Anderson (eds.). Handbook of environmental physiology of fruit crops. vol. 1. Temperate crops. CRC Press, Boca Raton, Fla.

Ourecky, D.K. and G.L. Slate. 1967. Behavior of the everbearing characteristics in strawberry. Proc. Amer. Soc. Hort. Sci. 91:236-241.

Powers, L. 1954. Inheritance of period of blooming in progenies of strawberries. Proc. Amer. Soc. Hort. Sci. 64:293-298.

SAS Institute. 1990. SAS/STAT user's guide, release 6.04. SAS Inst., Cary, N.C.

Scott, D. H. 1936. Size, firmness, and time of ripening of fruit of seedlings of Fragaria virginiana Duch. crossed with cultivated strawberry varieties. Proc. Amer. Soc. Hort. Sci. 74:388-393.

Shaw, D.V. 1995. Comparison of ancestral and current-generation inbreeding in an experimental strawberry breeding population. Theoret. Appl. Genet. 90:237-241.

Tourjee, K., J. Harding, and T.G. Byrne. 1995. Complex segregation analysis of Gerbera flower color. Heredity 74:303. 